\title{
Localization of NORs in the Nucleolus-DNA Body Complex of the Oocyte from the Nemertine Amphiporus Lactifloreus
}

\author{
Gérard Rué \\ Laboratoire de Biologie Cellulaire et Générale, Université de Champagne, B.P. \\ 347, F 51062 Reims, France
}

\begin{abstract}
The nucleus of the premeiotic oocyte from the hoplonemertine Amphiporus lactifloreus contains a characteristic DNA-rich body that rapidly generates a peculiar nucleolar apparatus previously described as the nucleolusDNA body complex. During early vitellogenesis, the nucleolar complex is centrally located in the nucleus and consists of many spherical and ribbonshaped components-the nucleolar spherulae and lamellae-which produce hundreds of small peripheral nucleoli and several granular bodies as vitellogenesis progresses. Distributions of the nucleolar organizer regions (NORs) in various nucleolar components were studied by silver staining, and results were compared with previous findings obtained by cytochemical and autoradiographic techniques.

The core of each spherula in the nucleolus-DNA body complex is strongly Ag-positive, and so, later on, is a minor part of each peripheral nucleolus. In contrast, the cortices of the nucleolar spherulae, in which slightly decondensed chromatin is distributed uniformly, and the nucleolar lamellae produced through self-peeling of the spherulae, do not react with silver. Thus, the NOR proteins identified by silver deposits correspond to numerous loci at which the most decondensed, transcriptionally active chromatin is made visible by the osmium-ammine reaction. These results are discussed in relation to the functional evolution of the initial DNA body of the oocyte from $A$. lactifloreus, the transcriptional abilities of its by-products, and the general process of the amplification of ribosomal genes.
\end{abstract}

The amplification of DNA coding for ribosomal RNA has been described in the oocytes of a number of species of vertebrates and invertebrates $(3,30,31,32,39)$; but, up to now, nemertine oocytes have not been studied. During oogenesis in nemertines, successive cytological features of the nucleus differ greatly according to whether the species belongs to the hoplonemertines or heteronemertines $(1,2)$. The nucleus of the premeiotic oocyte from the hoplonemertine Amphiporus lactifloreus contains a DNA-rich body that somewhat resembles the DNA body in the germ cells of insects $(7,8,26,28,30)$. During early vitellogenesis, this DNA body generates a peculiar, highly developed nucleolar apparatus, the nucleolus-DNA body complex, which has been described elsewhere (38).

The nucleolus-DNA body complex is made up of many spherical components (spherulae) and characteristic ribbon-shaped components (lamellae). It differentiates 
long before the several hundred peripheral nucleoli form, during the vitellogenic phase. Ultrastructural cytochemistry and high-resolution histoautoradiography has showed that the degree of condensation of chromatin fibers in the various parts of this compact DNA-rich nucleolar complex is related to their transcriptional potential. Thus, the DNA of the partly and regularly decondensed chromatin of both the nucleolar lamellae and the cortices of the nucleolar spherulae is not transcribed into RNA; whereas, the DNA of the more dispersed chromatin (cloudy chromatin) in the cores of the nucleolar spherulae is (38). Because during premeiosis and early vitellogenesis the nuclei of oocytes from $A$. lactifloreus do not have a structurally typical nucleolar apparatus whose activity can be easily studied from the organization of its ultrastructural components, I used several means to locate the transcriptionally active sites in this nucleolus-DNA body complex, in order to find out where and when during meiotic prophase rDNA transcription starts. I therefore used Agstaining, which makes visible the nucleolar organizer regions (NORs) both in light (17) and electron $(6,20)$ microscopy.

My results are compared with previous ones obtained by cytochemical techniques. Evidence is given for the amplification of ribosomal genes in the nucleolus-DNA body complex of the A. lactifloreus oocyte.

\section{MATERIALS AND METHODS}

Because the reproductive cycle of $A$. lactifloreus is annual, worms were collected along the shore of the English Channel once every 3 months from the juvenile period (spring) through the reproductive period (winter). Before the samples were processed for fixation, the worms were anesthetized with MS 222 (Sandoz).

For routine light microscopy, pieces from the genital segment were fixed in Bouin-Holland solution then embedded in paraffin wax. Sections were cut and stained with hemalun/ eosin. For detection of DNA by fluorescence, formaldehyde:ethanol:acetic acid (1:19:1), or Carnoy's solution, was the fixative. The fluorescence of the pararosaniline-stained preparations (4) was viewed with an Ortholux Leitz microscope equipped for reflected light fluorescence. Pararosaniline reagent was diluted 100-fold in comparison to the standard conditions of use. For the ultrastructural examination, small pieces from the genital region of the worm first were fixed for $90 \mathrm{~min}$ in $2.5 \%$ glutaraldehyde in a 6:15:5 mixture of $0.1 \mathrm{M}$ sodium cacodylate buffer, $\mathrm{pH} 7.4$, seawater and distilled water, then with $1 \% \mathrm{OsO}_{4}$ in $0.1 \mathrm{M}$ cacodylate buffer for $60 \mathrm{~min}$. After being thoroughly impregnated with a toluene/resin mixture, the samples were embedded in Epon 812 and sectioned. The ultrathin sections were stained first with uranyl acetate then with lead citrate.

The Ag-staining procedure was adapted from the one-step method (35) by raising the osmolarity of the fixative and the wash solution to 900 mosm with $\mathrm{NaCl}$. The pieces were fixed for $10 \mathrm{~min}$ at $4{ }^{\circ} \mathrm{C}$ in $1.6 \%$ glutaraldehyde in phosphate buffer, $\mathrm{pH} 7.2$, then washed in the same buffer and fixed again for $5 \mathrm{~min}$ at $4{ }^{\circ} \mathrm{C}$ in Carnoy's solution (ethanol :chloroform: acetic acid, 6:3:1). Between these two fixations, some pieces were treated with $0.05 \%$ RNAse (Boehringer-Mannheim) in phosphate buffer for $60 \mathrm{~min}$ at $60^{\circ} \mathrm{C}$. After a rinse and rehydration, the pieces were stained with $\mathrm{Ag}$ for 5 to $10 \mathrm{~min}$ at $70^{\circ} \mathrm{C}$ by placing them in a mixture $(1: 2)$ of $2 \%$ gelatin in $1 \%$ formic acid and $50 \%$ silver nitrate in distilled water. The stained pieces were carefully rinsed in distilled water then immersed in a solution of $5 \%$ thiosulfate and rinsed again, after which they were embedded in Epon and sectioned. The ultrathin sections, whether stained or not, were examined with a JEOL $100 \mathrm{C}$ electron 
microscope operating at $80 \mathrm{kV}$. Some Ag-stained pieces were squashed lightly between the slide and cover-glass then examined under a light microscope.

For the autoradiographic study, $\left[{ }^{3} \mathrm{H}\right]$ uridine (C.E.A., France) was used as the precursor at a concentration of $50 \mu \mathrm{Ci} / \mathrm{ml}$ in seawater. The worms were immersed in the radioactive medium for $60 \mathrm{~min}$ then rinsed in seawater before being anesthetized then fixed in $2.5 \%$ glutaraldehyde. These samples were rinsed for $48 \mathrm{~h}$ in a buffered cacodylate mixture before being postfixed in $1 \% \mathrm{OsO}_{4}$. The ultrathin sections were covered with $\mathrm{L}_{4}$ Ilford emulsion and developed after 6 weeks of exposure.

DNA was detected cytochemically on the ultrathin sections by a Feulgen-like method based on the use of osmium-ammine-SO $\mathrm{SO}_{2}(11,14)$.

\section{RESULTS}

In the hoplonemertine $A$. lactifloreus, the nucleolar apparatus (the nucleolus-DNA body complex) of the oocyte is made up of many structural components (Fig. 1a) produced progressively during early vitellogenesis from a DNA-rich body close to the nuclear envelope of premeiotic cells (Fig. 1b). Morphological and cytochemical evidence for the generation of various components of this nucleolar apparatus (spherulae and lamellae) from the heterochromatic DNA-rich body has been reported in light- and electron-microscopy studies (38). The examination, reported here, of the fluorescence from pararosaniline-stained preparations, is especially convincing because the fluorescence from the nucleolar spherulae (Fig. 1c) originated from the heterochromatic body present during prior stages (Fig. 1b).

In my ultrastructural examination of the nucleolar complex after Ag staining of the NOR, extensive silver deposits were found in all the nucleolar spherulae produced by growth and fragmentation of the previously formed heterochromatic body (Fig. 2). These deposits clearly were located in the core, not in the cortex (100 to $250 \mathrm{~nm}$ thick), of each spherula. At this early stage, however, a few core extensions in the cortex close to the nuclear envelope were stained. The autoradiographic study of the incorporation of $\left[{ }^{3} \mathrm{H}\right]$ uridine after a 60 -min incubation of the worms in seawater with added precursor showed that the main sites of incorporation of the radiolabelled precursor were in the spherula core, not in the spherula cortex nor the lamellae (Fig. 3).

At subsequent stages of oocyte development, the nucleolar complex moved away from the nucleolar envelope to the center of the germinative vesicle. At the same time it continued to grow and break up, and the spherical nucleolar fragments (spherulae), 2 to $4 \mu \mathrm{m}$ in diameter, peeled into large lamellae (Fig. 4). The cores of the numerous regular spherulae always reacted strongly to the silver salt (Fig. 5), but their cortices and the lamellae produced from the self-peeling of the spherulae were nonreactive (Fig. 6). Selective staining of the DNA in the ultrathin sections by a Feulgen-like osmium-ammine reaction made it possible to distinguish chromatin of two different textures in the nucleolar complex of early vitellogenic oocytes (38); a granular chromatin composed of 15- to 22-nm particles uniformly distributed in the lamellae and in the cortices of spherulae, and a fibrillar or "cloudy" chromatin composed of fibrillar elements 5 to $10 \mathrm{~nm}$ in diameter scattered in the spherulae cores (Fig. 7). A comparative study of the nucleolar spherulae and the lamellae, after silver or osmium ammine staining showed that the NOR proteins were closely related to the "cloudy" chromatin. 


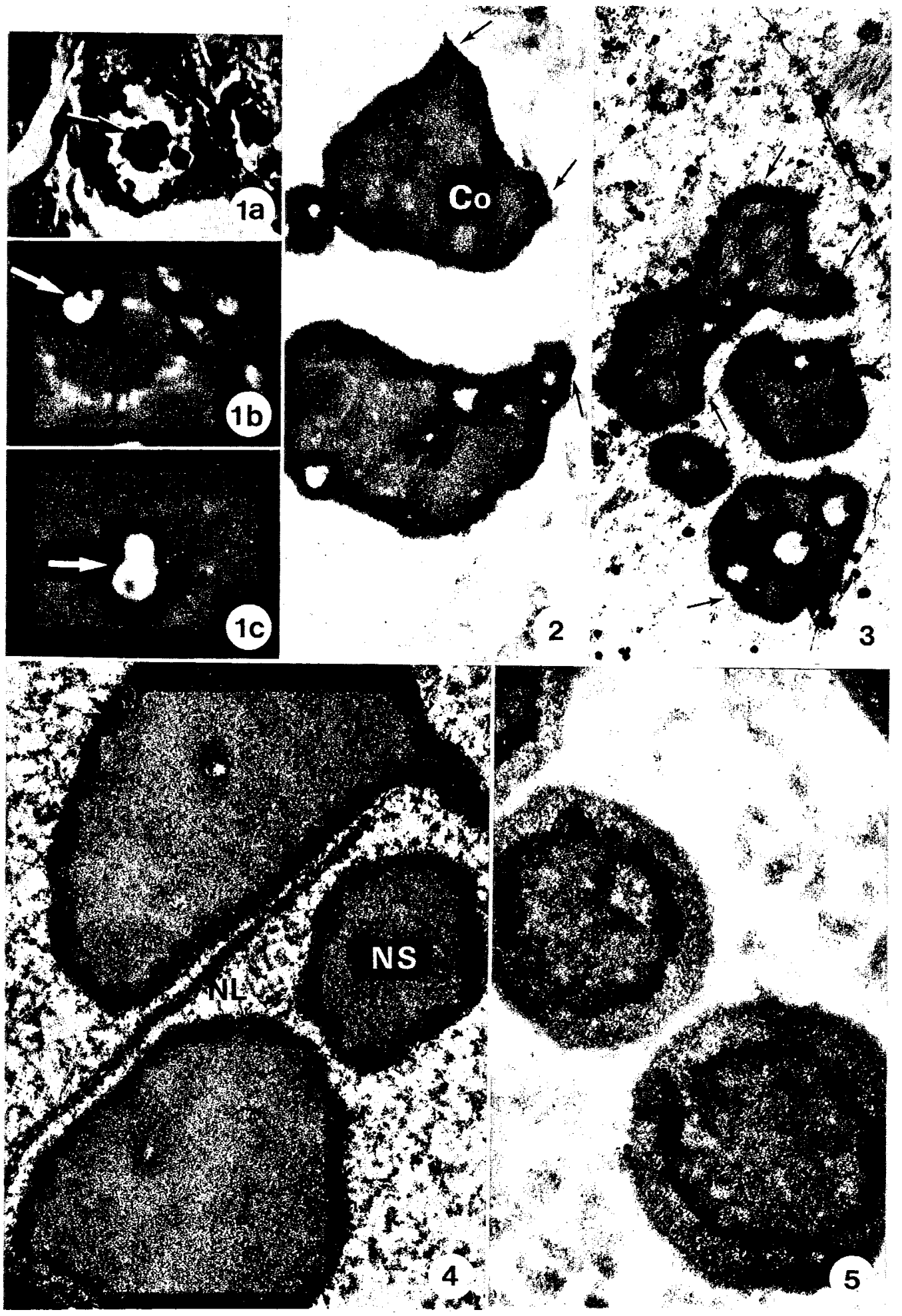




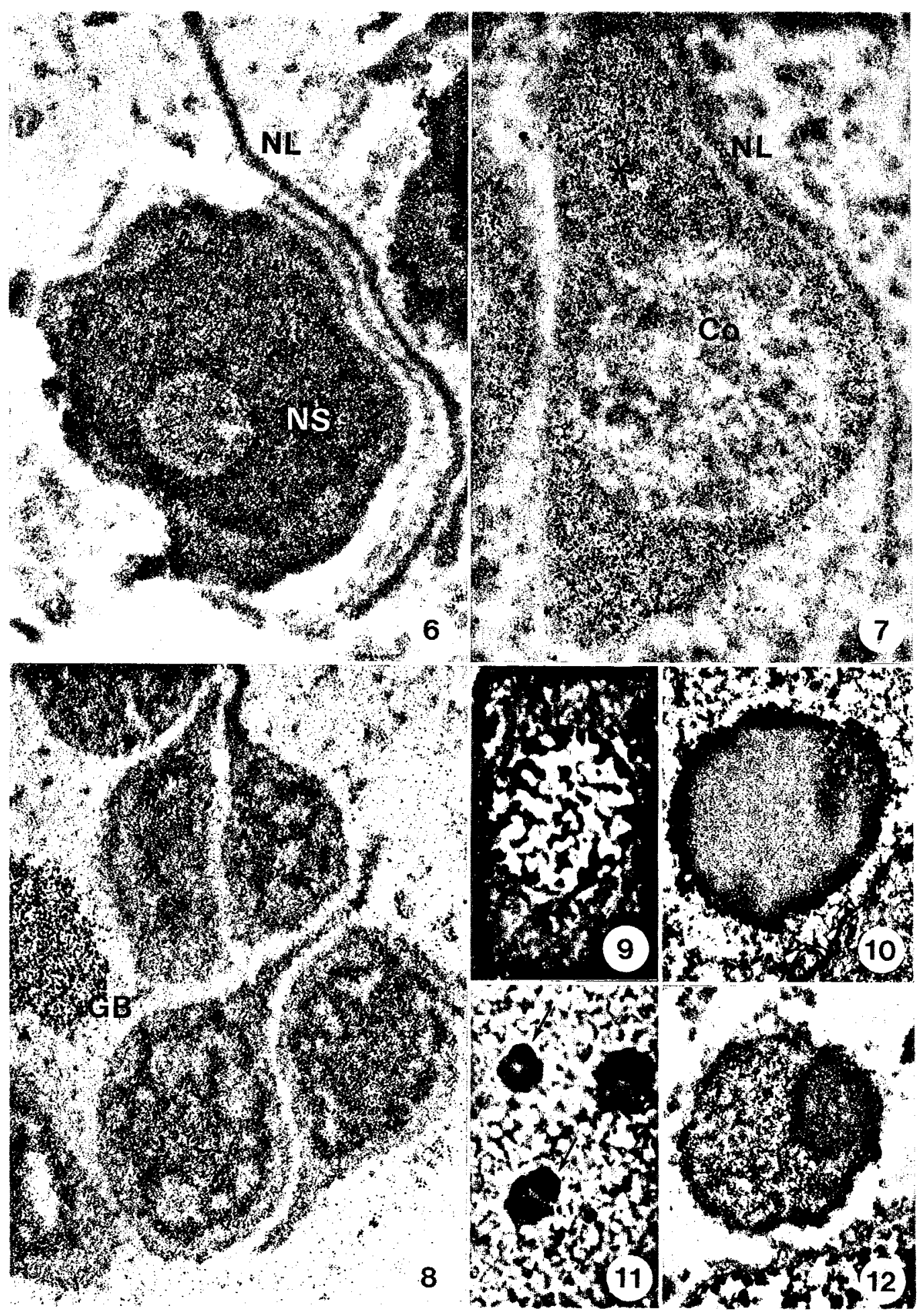


When the oocytes entered the vitellogenic phase, extensive silver deposits remained in the cores of the nucleolar spherulae; but, at this stage the metallic particles no longer were distributed uniformly but were arranged in loosely defined rows (50 to $80 \mathrm{~nm}$ thick) forming network-like structures (Fig. 8). Moreover, when many extrachromosomal nucleoli subsequently appeared in the nuclear area close to the nuclear envelope (Figs. 9 and 10), the scattered silver deposits were confined to a smaller polar region in each of these nucleoli (Figs. 11 and 12).

\section{DISCUSSION}

NOR proteins have been made visible in oocytes of the hoplonemertine $A$. lactifloreus by selective Ag-staining at different stages of development of the nucleolus-

Fig. 1. Development of the nucleolus-DNA body complex in an Amphiporus lactifloreus oocyte. Light microscopy. (a) Hemalum/eosin-stained nucleus in an oocyte during early vitellogenesis. The nucleolus-DNA body complex is centrally located and consists of coalesced nucleolar spherulae (arrow). $\times 700$. (b) Pararosaniline-stained nucleus in a premeiotic oocyte. Note the large fluorescent heterochromatic body close to the nuclear envelope (arrow). $\times 2,750$. (c) Pararosaniline-stained nucleus in an oocyte at the same stage as in (a). Note the highly fluorescent appearance of the components of the nucleolar complex (arrow). $\times 1,900$.

Figs. 2 and 3. Early fragmentation of the nucleolus-DNA body complex in an Amphiporus lactifloreus oocyte. Fig. 2. The eccentrically located nucleolar complex consists of a few compact nucleolar spherulae. After Ag-NOR staining, large silver deposits are present in each spherula core (Co), but the spherula cortex close to the nucleoplasm is devoid of such deposits. Note contacts (arrows) between the silver-stained area and nuclear envelope. $\times 16,500$. Fig. 3 . Electron microscopic autoradiography. The worms were incubated for $60 \mathrm{~min}$ in the presence of $\left[{ }^{3} \mathrm{H}\right]$ uridine. Silver granules are located mainly in the cores of spherulae, and the cortex usually is devoid of granules (arrows). $\times 8,750$.

Figs. 4 and 5. Nucleolus-DNA body complex in an early vitellogenic Amphiporus oocyte. Fig. 4. Glutaraldehyde-osmium fixation. Nuclear spherulae (NS) and lamellae (NL) dispersed in the nucleoplasm area have compact electron-dense structures. $\times 17,750$. Fig. 5. Ag staining of the NOR proteins. The distinct localization of the silver deposits in each spherula core is in marked contrast to the absence of silver granules in other regions of the nucleus. $\times 23,500$.

Figs. 6 and 7. Lamellae and spherulae in a nucleolus-DNA body complex from an Amphiporus oocyte during early vitellogenesis. Fig. 6. Ag staining of the NOR proteins. Note that there are silver deposits only in the central region of the nucleolar spherula (NS). The nucleolar lamellae (NL) did non stain. $\times 20,500$. Fig. 7. Glutaraldehyde fixation/DNA-specific staining with osmium/ ammine-SO $\mathrm{S}_{2}$. Stained, DNA-rich granules are present in a nucleolar lamella (NL) and in the cortex $\left(^{*}\right)$ of a spherula. "Cloudy" chromatin, more dispersed than in the cortex, can be seen in the core (Co) of the spherula. $\times 22,750$.

Fig. 8. Nucleolar complex in a vitellogenic Amphiporus oocyte. Ag staining of the NOR proteins after treatment of oocyte pieces with RNAse. Note the network-like organization of the silver deposits in the spherula cores. A granular body (GB) with regularly dispersed silver granules is present in the vicinity of the nucleolar spherulae. $\times 21,500$.

Figs. 9 and 10. Vitellogenic Amphiporus oocyte. Fig. 9. Light microscopy. Hemalun/eosin. Numerous extrachromosomal nucleoli are distributed regularly under the nuclear envelope. $\times 350$. Fig. 10. Glutaraldehyde-osmium fixation. Ultrastructural appearance of an extrachromosomal peripheral nucleolus. $\times 14,000$.

Figs. 11 and 12. Ag staining of NOR-proteins in vitellogenic Amphiporus oocytes. Fig. 11. Light microscopy. Peripheral nucleoli. Note the lateral location of the dense silver deposits in the nucleoli (arrows). $\times 3,250$. Fig. 12. Ultrastructural aspects of an extrachromosomal nucleolus at the stage shown in Fig. 11. Note the network-like organization of the silver deposits. $\times 14,000$. 
DNA body complex. This technique, often used to study the nucleoli of somatic cells (reviewed in 19,24) revealed the location of NOR proteins which show up as silver deposits in both the fibrillar centers and the dense fibrillar component of the nucleolus from interphase cells $(12,16,21,22,34,35)$. During early vitellogenesis, cytochemical and autoradiographic techniques used on the nucleolar complex of A. lactifloreus oocytes showed remarkable transcriptional activity within each of the numerous nucleolar components (38). But, these components did not have the same structural organization as the nucleoli from somatic cells, within which nucleoli usually are the result of the characteristic arrangement of three main components: the NOR chromatin, exclusively located in the fibrillar centers, the fibrillar ribonucleoprotein portion, and the granular ribonucleoprotein portion. The high chromatin content of the cortical areas in the spherical subunits of the nucleolar apparatus from $A$. lactifloreus oocytes that is associated with the dense structure of these subunits, suggests that they result from the development of the heterochromatic body that characterizes the nucleus of the premeiotic oocyte.

During early vitellogenesis, Ag-staining revealed the presence of NOR proteins in each of the first nucleolar by-products of the growth and fragmentation of the initial heterochromatic body of the oocyte nucleus. The location of the Ag-reactive area in cores of the first nucleolar spherulae and the same location for radioisotope labeling after a brief incubation of the genital pieces in $\left[{ }^{3} \mathrm{H}\right]$ uridine show that transcription in nucleolar spherulae actually is related to rRNA synthesis. These Ag-NOR proteins are present only in the cores of the nucleolar spherulae: the spherula cortex and the nucleolar lamellae are totally free of silver deposits.

Ultrathin sections of nucleolar spherulae and lamellae from nucleolar complexes at the same stage, treated by the Ag-NOR procedure or by the Feulgen-like reaction revealed, as postulated by Medina et al. (33) and Clavaguera et al. $(9,10)$, that the location of the Ag-stained NOR proteins is related to the degree of scattering of chromatin. The nucleolar lamellae and the spherula cortex, in both of which the chromatin appears granular and lightly decondensed, are nonreactive with the silver stain; whereas, the cores of the spherulae, in which very dispersed chromatin fibers appear (cloudy chromatin), react strongly with silver.

The presence of both thin chromatin fibers and Ag-stained NOR proteins in spherulae cores may be comparable to the presence of dispersed nucleolar DNA and Ag-stained NOR proteins in fibrillar centers and the fibrillar component of a typical nucleolus found by Hernandez-Verdun in a human cell line (20). Because the entire fibrillar core of each nucleolar spherula of the A. lactifloreus oocyte is the site of transcriptional activity, it does not correspond exactly to the fibrillar centers of the nucleolus sensu stricto (15), around which RNA transcription occurs. Functionally, the cores of nucleolar spherulae may correspond to the fibrillar component of the nucleolonema or to the dense fibrillar component usually seen in contact with the fibrillar centers, both strongly reactive to silver staining $(5,18,19,27,29,33)$.

The two different forms, coiled or uncoiled, of the chromatin fibers made visible by the Feulgen-like reaction in the nucleolar structures derived from the DNA body are suggested to correspond, respectively, to regions in which rDNA is untranscribed (the spherula cortex and nucleolar lamellae) and to regions is which it is transcribed (the core of the spherula). Because the cortex of the nucleolar spherulae is the source of the nucleolar lamellae, the rDNA-containing chromatin gradually becomes scattered in the nucleoplasm. This process seems to be a prerequisite for differen- 
tiation of the multiple peripheral nucleoli and granular bodies, and thus for the major phase of ribosomal transcription that takes place later in the oocyte during vitellogenesis.

By contrast, rDNA-containing chromatin located in the cores of the nucleolar spherulae may ensure the preliminary transcription of rRNA during early vitellogenesis. The expression "nucleolus-DNA body complex" is intended to encompass and define, both structurally and functionally, all the nucleolar structures that constitute the major components of the nucleus of the A. lactifloreus oocyte.

As far as I know, no ultrastructural study of silver-stained NOR proteins in nuclei of oocytes containing DNA bodies has ever been reported. In the oocyte of the house cricket Acheta domesticus, which has been studied extensively $(25,30,32$, 39), Ag-staining seen under light microscopy showed a totally different pattern of nucleolar organization: silver deposits surround the DNA body at the pachytene (23), when the "RNA-rich areas" form, and they are located in the inner core of the DNA body at the early diplotene, when subsequent fragmentation of the DNA body takes place (13).

The granular bodies that develop in the nucleus of $A$. lactifloreus oocytes during vitellogenesis often appear to be in close contact with the spherulae and lamellae of the nucleolar complex. This location and their positive response to regressive EDTA-staining (38) suggest a relation between these granular bodies and the nucleolar function.

It is generally accepted that the silver staining of NORs is linked to the dispersion of rDNA-rich chromatin rather than to its transcriptional activity $(9,10,33)$. In the nucleus of the $A$. lactifloreus oocyte, differentiation of the nucleolar complex leads to an increase in the number of spherulae which permits a concomitant increase in the number of loci (the cores of the spherulae) at which the chromatin is transcriptionally active or is ready to become activated. In contrast, silver deposits progressively became arranged in rows during vitellogenesis. This network-like organization of the metal particles, which also characterizes the multiple extrachromosomal nucleoli in the Xenopus oocyte (5), seems to be linked to the transcriptional activity of the rDNA.

The chromatin, which was lightly dispersed in the cortex of the spherulae, appeared to consist of uniformly distributed dense granules, but these did not react with the silver staining which characterized the potentially active NOR chromatin. During early vitellogenesis, newly differentiated spherulae were forming from the initial spherulae. Their cores were always strongly positive to silver staining, whereas nucleolar granular bodies differentiated close to the cortical regions of the spherulae or to the nucleolar lamellae which formed from the spherulae. These findings suggest the presence of rDNA-rich chromatin in the cortical regions of the numerous spherical subunits that make up the nucleolus-DNA body complex of the A. lactifloreus oocyte.

The growth and fragmentation of the DNA body of the A. lactifloreus oocyte into many spherical and polymorphous organelles, each transcriptionally active $(36,37)$, seem to be the origin of the development of the multiple small extra-nucleoli in the nucleoplasm that underlies the nuclear envelope during vitellogenesis. After silverstaining, each extra-nucleolus showed a conspicuous black precipitate, often situated laterally. This enlarged location of silver deposits in the nucleus confirms that all these nucleolar structures contain actively transcribed or transcribable rDNA 
cistrons, or both and demonstrates the existence of an original ribosomal gene amplification and distribution process in a marine ribbon worm.

Acknowledgements. I thank Prof. J. Bierne for his advice and help during the preparation of this manuscript, D. Brossard for her skillful technical assistance, and J. Leleu for the typing. This research was supported in part by grants from the Direction de la Recherche du Minstère de l'Education Nationale and the Université de Champagne à Reims.

\section{REFERENCES}

1. Bierne, J. Nemertina. In, Reproductive Biology of Invertebrates, eds. AdiYOdi K.G. and R.G. AdiYodi, J. Wiley \& Sons, New York, Vol. 1, pp. 147-167, 1983

2. Bierne, J. and G. Rue. Endocrine control of reproduction in two rhynchocoelan worms. Int. J. Invertebr. Reprod. 1, 109-120, 1979

3. BIRD, A.P. Gene reiteration and gene amplification. In, Cell Biology, eds. Goldstein L. and D.P. Prescott, Academic Press, New York, pp. 62-111, 1980

4. Bohm, N., E. Sprenger and W. Sandritter. Absorbance and fluorescence cytophotometry of nuclear DNA. A comparative study. In, Fluorescence Techniques in Cell Biology, eds. THAER A.A. and M. Sernetz, Springer-Verlag, Berlin, pp. 67-77, 1973

5. BoloukHere, M. Ultrastructural localization of nuclear organizers during oogenesis in Xenopus laevis using a silver technique. J. Cell. Sci. 65, 73-93, 1984

6. Bourgeois, C.A., D. Hernandez-Verdun, J. Hubert and M. Bouteille. Silver staining of NORs in electron microscopy. Exp. Cell Res. 123, 449-452, 1979

7. CAve, M.D. Localization of ribosomal DNA within oocytes of the house cricket, Acheta domesticus (Orthoptera: Gryllidae). J. Cell Biol. 55, 310-321, 1972

8. CAVE, M.D. and E.R. Allen. Extrachromosomal DNA in early stages of oogenesis in Acheta domesticus. J. Cell Sci. 4, 593-609, 1969

9. Clavaguera, A., E. Querol, D. Coll, J. Genesca and J. Egozcue. Cytochemical studies on the nature of NOR (nucleolus organizer region) silver stainability. Cell. Mol. Biol. 29, 255-259, 1983

10. Clavaguera, A., E. Querol, D. Coll and J. Egozcue. Is silver stainability of nucleolar organizer regions exclusively attributable to proteins? Cell. Mol. Biol. 30, 175-177, 1984

11. Cogliati, R. and A. Gautier. Mise en évidence de l'ADN et des polysaccharides à l'aide d'un nouveau réactif “de type Schiff”. C.R. Acad. Sci. Ser. D. 276, 3041-3044, 1973

12. Couve, E. and P. EspondA. Analysis of nucleolar components by combined silver staining and serial sections procedures. Cell Biology International Reports 6, 659-667, 1982

13. Czaker, R. Silver staining in transcriptionally active NORs of meiotic and mitotic cells in Acheta domesticus (L.) (Orthoptera). Chromosoma 68, 187-193, 1978

14. Gautier, A. Ultrastructural localization of DNA in ultrathin tissue sections. Int. Rev. Cytol. 44, 113-191, 1976

15. Goessens, G. and A. Lepoint. The nucleolus-organizing regions (NOR's): recent data and hypotheses. Biol. Cell 35, 211-220, 1979

16. Goessens, G. and A. LePOINT. Localization of Ag NOR-proteins in Ehrlich tumor cell nucleoli. Biol. Cell 43, 139-142, 1982

17. Goodpasture, C. and S.E. Bloom. Visualization of nucleolar organizer regions in mammalian chromosomes using silver staining. Chromosoma 53, 37-50, 1975

18. Hartung, M., J.W. Keeling, C. Patel, M. Bobrow and A. Stahl. Nucleoli, micronucleoli, and nucleolus-like structures in human oocytes at meiotic prophase I studied by the silver-NOR technique. Cytogen. Cell Genet. 35, 2-8, 1983

19. Hernandez-Verdun, D. The nucleolar organizer region. Biol. Cell 49, 191-202, 1983

20. Hernandez-Verdun, D., J. Hubert, C. Bourgeois and M. Bouteille. Identification ultrastructurale de l'organisateur nucléolaire par la technique à l'argent. C.R. Acad. Sci. 287, 1421-1423, 1978 
21. Hernandez-Verdun, D., J. Hubert, C. Bourgeois and M. Bouteille. Ultrastructural localization of Ag-NOR stained proteins in the nucleolus during the cell cycle and in other nucleolar structures. Chromosoma 79, 349-362, 1980

22. Hernandez-Verdun, D., M. Derenzini and M. Bouteille. The morphological relationship in electron microscopy between NOR-silver proteins and intranucleolar chromatin. Chromosoma 85, 461-473, 1982

23. Howell, W.M. Visualization of ribosomal gene activity: silver stains proteins associated with rRNA transcribed from oocyte chromosomes. Chromosoma 62, 361-367, 1977

24. Howell, W.M. Selective staining of nucleolus organizer regions (NORs). In, The Cell Nucleus, eds. Busch, H. and L. Rothblum, Acad. Press, New York, Vol. 11, pp. 89-142, 1982

25. Jaworska, H. and A. Lima-De-Faria. Amplification of ribosomal DNA in Acheta. VI Ultrastructure of two types of nucleolar components associated with ribosomal DNA. Hereditas 74, 169-186, 1973

26. KLOC, M. Extrachromosomal DNA and its activity in RNA synthesis in oogonia and oocytes in the pupal ovary of Creophilus maxillosus (Staphylinidae: Coleoptera-Polyphaga). Eur. J. Cell Biol. 21, 328-334, 1980

27. KNIBIEHLer, B. and C. Mirre. Involvement of argyrophilic proteins in transcription of nucleolar DNA in mouse spermatocytes. Biol. Cell 47, 379-382, 1983

28. KunZ, W. The origin of multiple oocyte nucleoli from accessory DNA bodies in Gryllus domesticus. Chromosoma 26, 41-75, 1969

29. Lafarga, M., J.P. Hervas, M.C. Santa-Cruz, J. Villegas and D. Crespo. The "accessory body" of Cajal in the neuronal nucleus. A light and electron microscopic approach. Anat. Embryol. 166, 19-30, 1983

30. Lima-De-FARIA, A. DNA replication and gene amplification in heterochromatin. In, Handbook of Molecular Cytology, ed. A. Lima-De-FARIA, North-Holland, Amsterdam, pp. 227325, 1969

31. MacGregor, H.C. The nucleolus and its genes in amphibian oogenesis. Biol. Rev. 47, 177-210, 1972

32. MacGregor, H.C. Ways of amplifying ribosomal genes. In, The Nucleolus, eds. JordAN, E.G. and C.A. Cullis, Cambridge University Press, Cambridge, Vol. 15, pp. 129-152, 1982

33. Medina, F.J., M.C. Risueno, M.A. Sanchez-Pina and M.E. Fernandez-Gomez. A study on nucleolar silver staining in plant cells. The role of argyrophilic proteins in nucleolar physiology. Chromosoma 88, 149-155, 1983

34. Pebusque, M.J., M. Vio and R. Seite. Ultrastructural location of Ag-NOR stained proteins in nucleoli of rat sympathetic neurons during dark period. Biol. Cell 40, 151-154, 1981

35. Ploton, D., H. Bовichon and J.J. Adnet. Ultrastructural localization of NOR in nucleoli of human breast cancer tissues using a one-step Ag-NOR staining method. Biol. Cell 43, 229232, 1982

36. Rue, G. and J. BIERne. Contrôle endocrinien de l'oogenèse chez l'Hoplonémerte Amphiporus lactifloreus. Bull. Soc. Zool. Fr. 105, 155-163, 1980

37. Rue, G. and J. Bierne. Synthèse de RNAs et de protéines dans les oocytes d'Hoplonémertes soumis et soustraits à l'influence de la gonadostatine (GIH). J. Physiol., Paris 78, 579-585, 1982

38. Rue, G. and J. Bierne. An ultrastructural and cytochemical study of the nucleolus-DNA body complex of Amphiporus lactifloreus oocytes. Biol. Cell 49, 203-212, 1983

39. Smetana, K. and H. Busch. The nucleolus and nucleolar DNA. In, The Cell Nucleus, ed. Busch, H. Academic Press, New York, Vol. 1, pp. 73-147, 1974

(Received for publication, July 14, 1986) 